\title{
Knowledge of symptoms and diagnostic possibilities of cancer diseases
}

\author{
Elżbieta Kozłowska', Maria T. Szewczyk ${ }^{1,2}$, Zbigniew Banaszkiewicz², Arkadiusz Jawień², \\ Katarzyna Cierzniakowska ${ }^{1,2}$, Pawet Jarmocik ${ }^{2}$
}

1Department of Surgery Nursing, Ludwik Rydygier Collegium Medicum, UMK, Bydgoszcz, Poland

2Department of Surgery Ludwik, Rydygier Collegium Medicum, UMK, Bydgoszcz, Poland

Submitted: 9 February 2010

Accepted: 21 April 2010

Arch Med Sci 2011; 7, 2: 304-309

DOI: $10.5114 /$ aoms.2011.22082

Copyright ๑ 2011 Termedia \& Banach

\author{
Corresponding author: \\ Maria T. Szewczyk \\ Department of Surgery \\ of Ludwik Rydygier \\ Collegium Medicum \\ 75 Ujejskiego \\ 85-168 Bydgoszcz, Poland \\ Phone: +48523655232 \\ Fax: +48523655782 \\ E-mail: mszewczyk@cm.umk.pl
}

\begin{abstract}
Introduction: The aim of the present study was to analyse patients' knowledge in the field of neoplastic prophylaxis.

Material and methods: The research was carried out between 2007 and 2008 in the Provincial Hospital in Bydgoszcz (i.e. general surgery, gynaecology and obstetrics, urology, breast surgery and thoracic surgery). Altogether 300 patients (of whom 250 were hospitalized) as well as 50 healthy subjects forming the control group were invited to participate in the study. A proprietary questionnaire containing eight multiple choice and another twelve open-ended questions was used for the purpose of the study.

Results: Prostate and lung cancer patients were more aware of their diseases compared to the control group, but the differences were not significant ( $p=0.85$ and $p=0.53$ respectively). In the field of screening the patients' knowledge, it was significantly higher in breast cancer subjects $(p=0.0008)$ while there was no difference compared to the control group in the remaining groups of cancer patients (i.e. colorectal, prostate or uterus cancer). Those most aware of their condition were patients from small towns (below 50,000), while subjects living in villages were the least aware.

Conclusions: Patients showed the greatest amount of knowledge regarding breast cancer and the least amount regarding prostate cancer. Oncological awareness in cancer patients was found to be related to variables such as education, age and residence. No difference was found between patients and controls, comparing their knowledge of disease symptoms as well as screening possibilities.
\end{abstract}

Key words: cancer, knowledge, symptoms, screening.

\section{Introduction}

Cancer diseases are a problem of today's civilization. They are one of the most dangerous groups of diseases that worries humanity, and the number of cases and deaths is still rising [1, 2]. It has been estimated that a half of cancer disease cases could have been prevented. It is known that effective prophylaxis against cancer diseases exists, that progress in the branch of oncology is enormous, that many malignant neoplasms can be cured and in many cases lifespan can be significantly lengthened and the quality of life can be improved $[3,4]$. However, often lack of time, fear of 
disease or a false shame are enough to postpone diagnostic testing. The most important seems to be the improvement of people's health awareness and the ability to see alarming symptoms in order to minimize the fear of cancer. Appropriate education and screening tests could be the key to minimize the incidence of disease and mortality from malignant neoplasms (NZ) [5-9].

\section{Material and methods}

The assessment of knowledge was conducted regarding clinical symptoms and the possibilities of screening tests for malignant neoplasms which occur most often among hospitalized patients in wards specializing in treating neoplasms. The research was conducted between 2007 and 2008 in the SP ZOZ Jan Biziel Provincial Hospital in Bydgoszcz in the: General Surgery Clinical Ward, Obstetrics Ward, Women's Diseases and Gynaecology as well as the Urology Ward, and also in the Oncology Centre in Bydgoszcz in the Breast Diseases Ward and in the Clinical Ward of Breast and Neoplasms Surgery. Taking part in these tests were 250 patients hospitalized in these hospitals and 50 healthy people as a control group, selected from the employees of the Solec Kujawski Town Hall. The research method was in the form of a specially constructed questionnaire. The respondents were of a different age, sex, place of residence and level of education. The following was assumed: if at least one of the basic symptoms or methods of test screening was correctly mentioned by the patient, it would then be considered that the knowledge of symptoms and screening methods was adequate. The analysis of associations was carried out by Pearson's linear correlation and values of $p<0.05$ were considered statistically significant. The Bioethics Committee of the Collegium Medicum in Bydgoszcz, Nicolaus Copernicus University in Torun approved the studies.

\section{Results}

From the group of 300 people tested, 142 people were hospitalized due to a malignant neoplasm $(\mathrm{MN})$ of different locations. Knowledge of clinical symptoms in five of the most common malignant neoplasms in people diagnosed with MN was analysed and compared with the group of healthy people. It was discovered that people with MN had a better knowledge of the clinical symptoms of cancer than the control group. The differences were not statistically significant. Knowledge of clinical symptoms of breast cancer, colon cancer and cervical cancer was worse among people hospitalized for MN. The difference was statistically significant $(p=0.033851)$ only in relation to knowledge of breast cancer symptoms (Table I).

Knowledge of methods for early detection of the most common MN among people with diagnosed $M N$ is very similar to the knowledge of healthy people. There were no statistically significant differences found concerning knowledge of screening methods of colon cancer, prostate cancer and cervical cancer. However, a larger percentage of people from the group without MN knew the principles of breast cancer screening. This difference was statistically significant ( $p=0.000824$, Table II).

The tested group was very heterogeneous in age. Knowledge of clinical symptoms and screening tests varied depending on age. The largest percentage of people without knowledge of the most common clinical symptoms of MN was found in the youngest and the oldest tested groups. Differences in knowledge of symptoms and screening tests of breast cancer and prostate cancer depending on the age of the tested people are statistically interchangeable (Tables III-VI).

After the analysis of knowledge of the most common clinical symptoms of $\mathrm{MN}$ in Poland depending on the place of residence, it was found that the largest percentage of people who are familiar with these symptoms live in cities with a population under 50,000 inhabitants, and the smallest percentage live in villages. The differences were statistically significant in relation to knowledge of clinical symptoms of breast cancer, colon cancer, prostate cancer and cervical cancer (Tables VII-X).

Table I. Comparison of knowledge about symptoms of breast cancer among patients with and without an $\mathrm{MN}$ diagnosis

\begin{tabular}{|lccc|}
\hline Symptoms of breast & Doesn't know & Knows & Total \\
\hline People with MN & $38.03 \%$ & $61.97 \%$ & $100 \%$ \\
\cline { 2 - 4 } & 54 & 88 & 142 \\
\hline People without MN & $26.58 \%$ & $73.42 \%$ & $100 \%$ \\
\cline { 2 - 4 } & 42 & 116 & 158 \\
\hline Total & 96 & 204 & 300 \\
\hline
\end{tabular}

$p=0.033851$

Table II. Comparison of knowledge regarding breast cancer screening among patients with and without MN diagnosis

\begin{tabular}{|lccc|}
\hline $\begin{array}{l}\text { Breast cancer } \\
\text { screening }\end{array}$ & Doesn't know & Knows & Total \\
\hline People with MN & $47.89 \%$ & $52.11 \%$ & $100 \%$ \\
\cline { 2 - 4 } & 68 & 74 & 142 \\
\hline People without MN & $29.11 \%$ & $70.89 \%$ & $100 \%$ \\
\cline { 2 - 4 } & 46 & 112 & 158 \\
\hline Total & 114 & 186 & 300 \\
\hline
\end{tabular}

$p=0.000824$ 
Table III. Comparison of knowledge regarding symptoms of breast cancer depending on age

\begin{tabular}{|lcccc|}
\hline $\begin{array}{l}\text { Age [years] } \\
\text { symptoms of } \\
\text { breast cancer }\end{array}$ & $\begin{array}{c}\text { Doesn't } \\
\text { know }\end{array}$ & $\%$ & Knows & $\%$ \\
\hline $16-30 / n=38$ & 8 & 21.05 & 30 & 78.95 \\
\hline $31-50 / n=94$ & 22 & 23.40 & 72 & 76.60 \\
\hline $51-70 / n=138$ & 52 & 37.68 & 86 & 62.32 \\
\hline Over $70 / n=30$ & 14 & 46.67 & 16 & 53.33 \\
\hline Total $/ n=300$ & 96 & & 204 & \\
\hline
\end{tabular}

$p=0.016212$

Table IV. Comparison of knowledge regarding symptoms of prostate cancer depending on age

\begin{tabular}{|lcccc|}
\hline $\begin{array}{l}\text { Age [years]/ } \\
\text { symptoms of } \\
\text { prostate cancer }\end{array}$ & $\begin{array}{c}\text { Doesn't } \\
\text { know }\end{array}$ & $\%$ & Knows & $\%$ \\
\hline $16-30 / n=38$ & 31 & 81.58 & 7 & 18.42 \\
\hline $31-50 / n=94$ & 54 & 57.45 & 40 & 42.55 \\
\hline $51-70 / n=138$ & 99 & 71.74 & 39 & 28.26 \\
\hline Over $70 / n=30$ & 24 & 80 & 6 & 20 \\
\hline Total $/ n=300$ & 208 & & 92 & \\
\hline$p=0.012247$ & & & & \\
\end{tabular}

Knowledge concerning breast and cervical cancer screening tests is found in a large percentage of tested people. There can be considerable variation depending on the place of residence. The largest percentage of people who know these principles reside in small cities and the smallest percentage reside in villages. These differences are statistically significant (Tables XI-XII). Knowledge about screening tests which are used in the early detection of colon and prostate cancer is far worse and does not depend on the place of residence.

Knowledge of the most common clinical symptoms of $\mathrm{MN}$ is the worst in the group of
Table V. Comparison of knowledge regarding prostate cancer screening depending on age

\begin{tabular}{|lcccc|}
\hline $\begin{array}{l}\text { Age [years]/ } \\
\text { prostate cancer } \\
\text { screening }\end{array}$ & $\begin{array}{c}\text { Doesn't } \\
\text { know }\end{array}$ & $\%$ & Knows & $\%$ \\
\hline $16-30 / n=38$ & 38 & 100 & 0 & 0 \\
\hline $31-50 / n=94$ & 71 & 75.53 & 23 & 24.47 \\
\hline $51-70 / n=138$ & 115 & 83.33 & 23 & 16.67 \\
\hline Over $70 / n=30$ & 24 & 80 & 6 & 20 \\
\hline Total $/ n=300$ & 248 & & 52 & \\
\hline
\end{tabular}

$p=0.009321$

Table VI. Comparison of knowledge regarding breast cancer screening depending on age

\begin{tabular}{|lcccc|}
\hline $\begin{array}{l}\text { Age [years]/ } \\
\text { breast cancer } \\
\text { screening }\end{array}$ & $\begin{array}{c}\text { Doesn't } \\
\text { know }\end{array}$ & $\%$ & Knows & $\%$ \\
\hline $16-30 / n=38$ & 14 & 36.84 & 24 & 63.16 \\
\hline $31-50 / n=94$ & 29 & 30.85 & 65 & 69.15 \\
\hline $51-70 / n=138$ & 55 & 39.86 & 83 & 60.14 \\
\hline Over $70 / n=30$ & 18 & 53.33 & 12 & 46.67 \\
\hline Total $/ n=300$ & 116 & & 184 & \\
\hline$P=0.154003$ & & & & \\
\hline
\end{tabular}

people with primary education. In this group it was found that there are 2-5 times fewer people with such knowledge as compared to those with secondary and higher education. These differences were statistically significant (Table XIII).

The knowledge of the possibilities to conduct screening tests for early detection of the most common MN in the tested group depended on education. The possibilities of conducting screening tests are best known to those with secondary and higher education. Statistically significant differences were found in the knowledge of screening for prostate cancer and cervical cancer (Tables XIV-XV).

Table VII. Comparison of knowledge regarding symptoms of breast cancer depending on the place of residence

\begin{tabular}{|c|c|c|c|c|}
\hline Place of residence/symptoms of breast cancer & Doesn't know & $\%$ & Knows & $\%$ \\
\hline City over 50,000 habitants $/ n=135$ & 47 & 34.81 & 88 & 65.19 \\
\hline City under 50,000 habitants $/ n=109$ & 20 & 18.35 & 89 & 81.65 \\
\hline Village $/ n=56$ & 29 & 51.79 & 27 & 48.21 \\
\hline Total $/ n=300$ & 96 & & 204 & \\
\hline
\end{tabular}

$p=0.000048$

Table VIII. Comparison of knowledge regarding symptoms of colon cancer depending on the place of residence

\begin{tabular}{|c|c|c|c|c|}
\hline Place of residence/symptoms of colon cancer & Doesn't know & $\%$ & Knows & $\%$ \\
\hline City over 50,000 inhabitants $/ n=135$ & 81 & 60 & 54 & 40 \\
\hline City under 50,000 inhabitants $/ n=109$ & 51 & 46.79 & 58 & 53.21 \\
\hline Village $/ n=56$ & 39 & 69.64 & 17 & 30.36 \\
\hline Total $/ n=300$ & 171 & & 129 & \\
\hline
\end{tabular}


Table IX. Comparison of knowledge regarding symptoms of prostate cancer depending on the place of residence

\begin{tabular}{|lcccc|}
\hline Place of residence/symptoms of prostate cancer & Doesn't know & $\%$ & Knows & 32 \\
\hline City over 50,000 inhabitants $/ n=135$ & 103 & 76.30 & 55.96 & 48 \\
\hline City under 50,000 inhabitants $/ n=109$ & 61 & 78.57 & 12 & 21.43 \\
\hline Village $/ n=56$ & 44 & & 92 \\
\hline Total $/ n=300$ & 208 & & \\
\hline
\end{tabular}

$p=0.000715$

Table X. Comparison of knowledge regarding symptoms of cervical cancer depending on the place of residence

\begin{tabular}{|lcccc|}
\hline Place of residence/symptoms of cervical cancer & Doesn't know & $\%$ & Knows & $\%$ \\
\hline City over 50,000 inhabitants $/ n=135$ & 79 & 58.52 & 56 & 41.48 \\
\hline City under 50,000 inhabitants $/ n=109$ & 49 & 44.95 & 60 & 55.05 \\
\hline Village $/ n=56$ & 42 & 75 & 14 & 25 \\
\hline Total $/ n=300$ & 170 & & 130 & \\
\hline
\end{tabular}

$p=0.000940$

Table XI. Comparison of knowledge regarding breast cancer screening depending on the place of residence

\begin{tabular}{|lcccc|}
\hline Place of residence/breast cancer screening & Doesn't know & $\%$ & Knows & $\%$ \\
\hline City over 50,000 inhabitants $/ n=135$ & 60 & 44.44 & 75 & 55.56 \\
\hline City under 50,000 inhabitants $/ n=109$ & 24 & 22.02 & 85 & 77.89 \\
\hline Village $/ n=56$ & 30 & 53.57 & 26 & 46.43 \\
\hline Total $/ n=300$ & 114 & & 186 & \\
\hline
\end{tabular}

$p=0.000046$

Table XII. Comparison of knowledge regarding colon cancer screening depending on the place of residence

\begin{tabular}{|lcccc|}
\hline Place of residence/colon cancer screening & Doesn't know & $\%$ & Knows & $\%$ \\
\hline City over 50,000 inhabitants $/ n=135$ & 87 & 64.44 & 48 & 35.56 \\
\hline City under 50,000 inhabitants $/ n=109$ & 70 & 64.22 & 39 & 35.78 \\
\hline Village $/ n=56$ & 34 & 60.71 & 22 & 39.29 \\
\hline Total $/ n=300$ & 191 & & 109 & \\
\hline
\end{tabular}

$p=0.877764$

\section{Discussion}

The majority of tests conducted around the world concerning neoplasm epidemiology concentrate mainly on the introduction of modern therapeutic methods in particular types of neoplasms. The authors emphasize the importance of prophylaxis in early diagnostics, but still there are few works which are devoted to the appearance of cancer diseases depending on the degree of people's awareness [10]. In research which was carried out 10 years ago, Chojnacka-Szawłowska found that the knowledge of clinical symptoms of cancer is better among people with cancer disease [11]. In our research, in a group of 300 people it was found that knowledge of the most common MN symptoms in Poland is on very different levels. A significant majority of people know the clinical symptoms of breast cancer (204/300), and a minority know the symptoms of prostate cancer (92/300). Knowledge regarding breast cancer screening tests is at the highest level; it is known by $2 / 3$ of the respondents tested $(186 / 200)$. The worst concerns prostate cancer $(52 / 300)$. The age of the respondents has a large influence on their knowledge about clinical symptoms and screening tests. In the 31-70 year age group this knowledge is the best. People under 31 and over 70 have a significantly worse

Table XIII. Comparison of knowledge regarding MN symptoms depending on education

\begin{tabular}{|lc|}
\hline Type of MN & Value of $p$ \\
\hline Lung cancer & 0.002390 \\
\hline Breast cancer & 0.005 \\
\hline Colon cancer & 0.000005 \\
\hline Prostate cancer & 0.001408 \\
\hline Cervical cancer & 0.000107 \\
\hline
\end{tabular}


Table XIV. Comparison of knowledge regarding prostate cancer screening depending on education

\begin{tabular}{|c|c|c|c|c|}
\hline Education/prostate cancer screening & Doesn't know & $\%$ & Knows & $\%$ \\
\hline Primary $/ n=38$ & 34 & 89.47 & 4 & 10.53 \\
\hline Vocational $/ n=77$ & 68 & 88.31 & 9 & 11.69 \\
\hline Secondary $/ n=120$ & 103 & 85.83 & 17 & 14.17 \\
\hline Higher $/ n=65$ & 43 & 66.15 & 22 & 33.85 \\
\hline Total $/ n=300$ & 245 & & 52 & \\
\hline
\end{tabular}

Table XV. Comparison of knowledge regarding cervical cancer screening depending on education

\begin{tabular}{|c|c|c|c|c|}
\hline Education/cervical cancer screening & Doesn't know & $\%$ & Knows & $\%$ \\
\hline Primary $/ n=38$ & 27 & 71.05 & 11 & 28.95 \\
\hline Vocational/n=77 & 51 & 66.23 & 26 & 33.77 \\
\hline Secondary $/ n=120$ & 64 & 53.33 & 56 & 46.67 \\
\hline Higher $/ n=65$ & 22 & 33.85 & 43 & 66.15 \\
\hline Total $/ n=300$ & 164 & & 136 & \\
\hline
\end{tabular}

$p=0.000194$

knowledge regarding it. The difference of knowledge regarding the clinical symptoms of breast and prostate cancer and knowledge of screening tests for the early detection of prostate cancer and colon cancer is statistically significant. It seems that one of the main reasons for this state is the lack of propositions for the most suggested screening tests for this group of people. On the basis of the research results it was found that awareness of MN is very bad in the villages. Only one in every three respondents had information regarding clinical symptoms appearing in patients with lung cancer or breast cancer, and in the case of prostate cancer, colon cancer and cervical cancer every fifth respondent. Koper et al. draw attention to the serious problems of access to information for people who live in small towns [12]. Much greater knowledge is shown by respondents from small towns (up to 50,000 inhabitants). This is probably due to better access to health care specialists. In small towns contact with the health services is easier, because there is usually only one hospital and a limited amount of specialist clinics. In big cities with a large amount of hospitals it is harder to coordinate public education activities. The level of knowledge regarding the most common $\mathrm{MN}$ in Poland depends on the level of education. Both knowledge about clinical symptoms and screening tests are directly proportional to education. The differences found are statistically significant. The biggest differences are related to knowledge regarding symptoms of colon and cervical cancer. Jokiel et al. carried out similar tests regarding changes in women's awareness and health behaviours concerning cervical cancer prophylaxis. The results of these tests were similar and confirmed that elderly women with the lowest education and who live in villages are the least likely to undergo prophylaxis tests [13]. This opinion is confirmed by Bannach et al. on the basis of tests carried out among women who live in the rural areas of Kujawsko-Pomorskie [14].

Knowledge regarding clinical symptoms of breast cancer and the possibilities of screening tests in the group of healthy people was shown by over $80 \%$ of the respondents $(88 \%$ and $82 \%$ respectively). Among hospitalized patients this knowledge is comparable. Only among patients treated in the Breast and Neoplastic Surgery Ward and the Clinical Surgery Ward is it significantly worse. It seems necessary to intensify public awareness related to MN. Mayo et al. believe that proper education is an essential condition for the effectiveness of screening tests [15]. In 2000 Paul et al. carried out tests on a group of 700 people who lived in Australia. The knowledge of screening tests was analysed and the results were compared to those from the year 1989. These tests confirmed the view that education conducted in the 1990s had a significant influence on raising health awareness [16]. It was proved that proper promotion, cooperation with family doctors and public awareness increase participation in the tests [17-19]. Patel et al. found that both after talking with a doctor and after the re-education of the society the participation in screening tests definitely increased ( $p<0.0001$ and $p<0.014$ respectively) [20]. Special attention should be given to rural residents, uneducated people, young people and those over 70 years old. Hurd et al. applied unconventional methods in the education of women regarding screening tests for cancer 
diseases. Its level was adjusted to the perceptive possibilities of a given group. Applying these methods there was an increase in participation by women in the programme by $79 \%$ [21]. In Poland there are many preventive and educational programmes for different groups in terms of age, sex, etc. Among the many programmes addressed e.g. to youth, the best known programme is "Mam haka na raka" (I have cancer on a hook).

In order to achieve the expected behaviour change and teach proper health habits it will take a number of years, and the process of education should be ongoing and long-term. That is why the inclusion of young people in this programme who are still at the early stages of developing good health attitudes is so important. Then there is a big chance to establish positive habits and behaviours to increase oncological awareness and thereby reduce the morbidity and mortality rates of cancer diseases.

In conclusion:

1) knowledge of the most common malignant neoplasms is varied; the best knowledge concerns breast cancer; the worst is prostate cancer;

2) no difference was found between patients and controls comparing their knowledge of symptoms of the disease as well as the screening possibilities;

3) oncological awareness depends on the age of the respondents; the greatest amount of knowledge of neoplasms is shown by respondents who are 31-50 years old;

4) the greatest amount of oncological knowledge is shown by respondents who live in small towns (under 50,000 habitants);

5) the higher the respondents' level of education, the higher their oncological awareness.

\section{References}

1. De Vita VT, Hellman S, Rosenberg SA, et al. Cancer: principles practice of oncology. $7^{\text {th }} \mathrm{Ed}$. USA, Philadelphia 2005; 217-41.

2. Jemal A, Siegel R, Ward E, et al. Neoplasm statistics. CA Cancer J Clin 2006; 56: 106-30.

3. Ayyub MI, Al-Radi AO, Khazeindar AM, et al. Clinicopathological trends in colorectal cancer in a tertiary care hospital. Saudi Med J 2002; 23: 160-3.

4. Celestino A, Castillo T, Frisancho O, et al. Colorectal cancer: study on 365 cases. Rev Gastroenterol Peru 1996; 16: 187-96.

5. Hawley ST, Vernon SW, Levin B, Vallejo B. Prevalence of colorectal cancer screening in a large medical organization. Cancer Epidemiol Biomarkers Prev 2004; 13: 314-9.

6. Banaszkiewicz Z, Szewczyk MT, Jarmocik P, Jawień A. Screening methods of colon cancer. In: Interdisciplinary assesment of health science. Bartuzi Z. Bydgoszcz 2007; 22-6.
7. Gonciarz M, Reguła J, Mularczyk A. Colon cancer the meaning of screening tests. New Clinic 2003; 10: 48-51.

8. Wronkowski Z, Zwierko M. Rules and results of model screening program of breast cancer and cervix cancer in Poland 1999-2000. Neoplasms 2002; 52: 72-9.

9. Spaczyński M, Nowak-Markwitz E, Kędzia W. Screening of cervix cancer in Poland and in the world. Pol Gynecol 2007; 78: 354-60.

10. Dobrzyń D, Starosolska H, Kołodziej W. Women's awareness of malignant neoplasms prophylaxis, Annales Universitatis Mariae Curie Skłodowska, Lublin, Vol. LVIII, Suppl XIII, 50, Sectio D, 2003; 272-6.

11. Chojnacka-Szawłowska G. Knowledge of the symptoms of cancer patients undergoing cancer diagnosis and the degree of clinical disease. Psychoonkologia 1998; 2: 27-36.

12. Koper A, Mierzwa T, Borzych B. Women's education about breast cancer prophylaxis in KujawskoPomorskie District. In: Selected aspects of medical treatment. Bartuzi Z. Bydgoszcz 2007; 197-204.

13. Jokiel $M$, et al. Changes in awareness and health reactions for cervix cancer prophylaxis in 1976, 1986, 1990 and 1998. Epidemiol Rev 2001; 55: 323-30.

14. Bannach M, Mierzwa T, Grabiec M, Walentowicz M. Health education influence on participation in prophylactic tests by women from the KujawskoPomorskie District. Ann Acad Med Siles 2005; 59: 4.

15. Mayo RM, Sherrill WW, Crew L, Watt P, Mayo WW. Connecting rural African American and Hispanic women to cancer education and screening: the Avon Health Connector project. J Cancer Educ 2004; 19: 123-6.

16. Paul C, Tzelepis F, Walsh RA, Girgis A, King L, McKenzie J. Has the investment in public cancer education delivered observable changes in knowledge over the past 10 years? Cancer 2003; 97: 2931-9.

17. Goel V, Gray R, Chart P, Fitch M, Saibil F, Zdanowicz Y. Perspectives on colorectal cancer screening: a focus group study" Health Expect 2004; 7: 51-60.

18. Myers RE, Turner B, Weinberg D, et al. Impact of a physician-oriented intervention on follow-up in colorectal cancer screening. Prev Med 2004; 38: 375-81.

19. O'Malley AS, Beaton E, Yabroff KR, Abramson R, Mandelblatt J. Patient and provider barriers to colorectal cancer screening in the primary care safety-net. Prev Med 2004; 39: 56-63.

20. Patel P, Forjuoh SN, Avots-Avotins A, Patel T. Identifying opportunities for improved colorectal cancer screening in primary care. Prev Med 2004; 39: 239-46.

21. Hurd TC, Muti P, Erwin DO, Womack S. An evaluation of the integration of non-traditional learning tools into a community based breast and cervical cancer education program: the Witness Project of Buffalo. BMC Cancer 2003; 3: 18. 